\title{
Fast Punicalagin Content Analysis of Various Brands of Pomegranate (Punica granatum L.) Juices by UPLC-MS
}

\section{Farklı Marka Nar (Punica granatum L.) Meyve Sularındaki Punikalajin İçeriğinin UPLC-MS ile Hızlı Şekilde Belirlenmesi}

\author{
Kemal Solakyıldırım ${ }^{\odot}$ \\ Erzincan Binali Yildirim University, Faculty of Science, Department of Chemistry, Erzincan, Turkey.
}

\section{A B STRACT}

unica granatum L., commonly known as pomegranate, has a good source of bioactive polyphenolic compounds that has been widely used as a traditional Chinese herbal medicine owing to their important biological properties including cardiovascular disease, arthritis, diabetes, and cancer. Commercial pomegranate juice is generally obtained via pressing whole pomegranate and its peels. Then, the most abundant ingredient, punicalagin, can be extracted into the juice. However, punicalagin levels may vary in commercial pomegranate juice and it can range from 0.017 to $2 \mathrm{~g} / \mathrm{L}$. In this study, we analyzed punicalagin content from six different brands of pomegranate juices by using UPLC-MS method. First, punicalagin standards were prepared from $50 \mu \mathrm{M}$ to $5 \mu \mathrm{M}$ in buffer A (0.1\% formic acid in water) and standard calibration curve was created. After that, three mass tune parameters including ionization voltage, desolvation temperature and source temperature of ESI source were optimized to obtain better peak shapes and correct quantification of the $\alpha$ - and $\beta$-isomer peaks of punicalagin. After analysis of six different brands of pomegranate juices, it was seen that punicalagin levels from different juice samples varied from 0.007 to $0.3 \mathrm{~g} / \mathrm{L}$.

\section{Key Words}

Punicalagin, pomegranate juice, UPLC, MS.

Öz

enel olarak nar olarak bilinen Punica granatum L., kardiyovasküler hastalık, artrit, diyabet ve kanser gibi önemli biyolojik

7 özellikleri nedeniyle geleneksel Çin bitkisel ilaçları olarak yaygın olarak kullanılan biyoaktif polifenolik bileşiklerin iyi bir kaynağına sahiptir. Ticari nar suyu genellikle bütün nar ve kabuklarını presleyerek elde edilir. Daha sonra, en bol miktarda madde olan punikalajin, meyve suyundan ekstre edilebilir. Ancak, punikalajin içeriği ticari nar suyunda farkılık gösterebilir ve 0.017 ila $2 \mathrm{~g} / \mathrm{L}$ arasında değişebilir. Bu çalışmada, UPLC-MS yöntemini kullanarak altı farklı marka nar suyunun punikalajin içeriğini analiz ettik. İlk olarak, punikalajin standartları, tampon A'da (su içinde\% 0.1 formik asit) $50 \mu M^{\prime}$ den $5 \mu M^{\prime}$ e uzanan derişim aralığında hazırlandı ve standart kalibrasyon eğrisi oluşturuldu. Daha sonra, iyonlaşma voltajı, desolvasyon sıcaklı̆̆ ve ESI kaynağının kaynak sıcaklığı dahil olmak üzere üç kütle ayar parametresi, daha iyi pik şekilleri elde etmek ve punikalajin a- ve $\beta$-izomer piklerinde doğru nicel analiz yapmak için optimize edildi. Altı farklı marka nar suyunun analizinden sonra farklı meyve suyu örneklerinden alınan punikalajin seviyelerinin 0.007 ila $0.3 \mathrm{~g} / \mathrm{L}$ arasında değiştiği görülmüştür.

\section{Anahtar Kelimeler}

Punikalajin, nar suyu, UPLC, MS.

Article History: Received: Dec 19, 2018; Revised: Jan 15, 2019; Accepted: May 28, 2019; Available Online: Sep 15, 2019.

DOI: https://doi.org/10.15671/hjbc.626949

Correspondence to: K. Solakyildirim, Department of Chemistry, Erzincan Binali Yildirim University, Erzincan, Turkey.

E-Mail: ksolakyildirim@erzincan.edu.tr 


\section{INTRODUCTION}

Dunica granatum L., commonly known as pomegranate, have become increasing popular because of their important biological actions including cardiovascular protection, cancer, Alzheimer disease, obesity, and diabetes [1-4]. Pomegranate flower extract was reported to improve cardiac lipid metabolism and diminish cardiac fibrosis in diabetic rats [5]. It was also shown that pomegranate extracts could be effective in the treatment and in particular prevention of type 2 diabetes [6].

Of the polyphenols found in pomegranate, punicalagin, the most abundant ellagitannin with the highest molecular weight, has been shown to have antioxidant and anti-inflammatory bioactivities $[7,8]$. Punicalagin is a high molecular weight polyphenolic compound which may produce beneficial effects by scavenging free radicals. Due to these properties, there has been an increasing interest in determining of such antioxidant sources $[9,10]$.

Commercial pomegranate juice compared to the other red fruit juices such as cranberry, blackberry and grape has the highest antioxidant activities $[11,12]$. This can be due to its high content of polyphenolic compounds including ellagic acid, gallic acid and other flavonoids $[13,14]$. More than 70 compounds (Phenolic acids, flavonoids, anthocyanins, and ellagitannins) have been detected $[15,16]$. Among these, punicalagin is the most abundant as indicated above. Commercial pomegranate juice is generally obtained via pressing whole pomegranate and its peels. Then, the most abundant ingredient, punicalagin, can be extracted into pomegranate juice. However, punicalagin levels may vary in commercial pomegranate juice due to fruit juice adulteration such as dilution, substitution and mislabeling [17] and it can range from 0.017 to $2 \mathrm{~g} / \mathrm{L}$ of pomegranate juice $[18,19]$.

The identification and quantification of phenolic compounds from plant and food matrices are a very crucial step when it comes to assess their biological functions. However, the full characterization of these compounds in fruits usually requires time consuming, expensive, and difficult methods owing to their complex structures. Instead, we thought monitoring punicalagin content as the most abundant and biologically important component of pomegranate juice would be relatively easy and effective way to determine authenticity of the juice samples for routine analysis.
In this study, we analyzed punicalagin amount from six different brands of pomegranate juices by using UPLCMS. First, punicalagin standards were prepared from $50 \mu \mathrm{M}$ to $5 \mu \mathrm{M}$ in buffer $\mathrm{A}$ ( $0.1 \%$ formic acid in water) and standard calibration curve was created. After that, three ionization parameters including ionization voltage, desolvation temperature and source temperature of electrospray ionization (ESI) source were optimized to obtain better peak shapes and accurate quantification of the $\alpha$ - and $\beta$-isomer peaks of punicalagin. After analysis of 6 different brands of pomegranate juices, it was shown that punicalagin levels from six different brand of pomegranate juices varied from 0.007 to 0.3 g/L.

\section{MATERIALS and METHODS}

\section{Apparatus and Reagents}

Acetonitrile (HPLC grade), methanol (HPLC grade) and formic acid (USP grade) were purchased from FisherScientific (Pittsburgh, PA). HPLC-grade water was from Burdick and Jackson (Morristown, NJ). Punicalagin standard was purchased from Sigma-Aldrich (St. Louis, MO). All high pressure chromatographic separations were performed with a $2.1 \mathrm{~mm} \times 150 \mathrm{~mm}$ Acquity $^{\mathrm{TM}}$ UPLC BEH C18 column with $1.7 \mu \mathrm{m}$ particles (Waters Corporation, MA). A guard column with an identical packing was used prior to the analytical column. Total ion chromatograms (TICS) were collected using a Micromass Q-TOF micro $^{\text {TM }}$ ESI quadrupole time-of-flight mass spectrometer (Waters Corporation, Milford, MA). Data acquisition was accomplished using MassLynx 4.1 software.

\section{Preparation of Samples and the Standard Curve:}

Quantification was based on the external standard method. Reference standard stock solution of punicalagin were prepared by dissolving the accurately weighed reference compounds in $0.1 \%$ formic acid in water to give a final concentration of $100 \mu \mathrm{M}$. The solution was then serially diluted with buffer A $0.1 \%$ formic acid in water) to obtain standard solutions from $50 \mu \mathrm{M}$ to 5 $\mu \mathrm{M}$. Peak areas were recorded for all the solutions. In order to prepare juice samples, six different brand of pomegranate juices were taken and centrifuged for 4 min. at 10,000 rpm. Then supernatant part was taken, diluted 15-times with buffer $A$, and then it was filtered through a $0.22 \mu \mathrm{m}$ membrane filter prior to injection.

\section{UPLC-ESI/MS analysis}

In order to provide the highest ionization efficiency, a 
punicalagin standard sample was infused directly to mass spectrometry. Mass method conditions were developed by optimizing the MS tune parameters for punicalagin analysis. After acquiring series of mass spectra under different experimental conditions, the best results were obtained by using following MS tune parameters in negative mode: The source voltage was $3000 \mathrm{~V}$, the desolvation temperature was $275^{\circ} \mathrm{C}$ and source temperature was $120^{\circ} \mathrm{C}$. The mass scan range was m/z 100-1200.

The punicalagin standards were analyzed using Waters BEH C18 column, $1.7 \mu \mathrm{m}$ particle size $(50 \times 2.1 \mathrm{~mm})$. The mobile phase $A$ was $0.1 \%$ formic acid in water and the mobile phase $B$ was $0.1 \%$ formic acid in acetonitrile. The flow rate was set at $0.5 \mathrm{ml} / \mathrm{min}$. The total separation took 20 min including post equilibration of the column. The gradient started with $98 \%$ A for $3 \mathrm{~min}$, and then 95\% A at 5 min followed by 5-min linear gradient from 95\% A to $90 \%$ A. From 10 to 13 min mobile phase A turned down to $70 \%$, followed to $1 \mathrm{~min}$ of $70 \%$ A. From 14 to 16 min, mobile phase A moved from $70 \%$ to $98 \%$ and then $4 \mathrm{~min}$ at the start conditions to re-equilibrate the column. The column temperature was set to $35^{\circ} \mathrm{C}$.

\section{The Method Validation}

Parameters including linearity, precision, accuracy, limit of detection and limit of quantification were investigated according to the ICH (Guidance for Industry: Bioanalytical Method Validation) [20].

\section{Linearity:}

Linearity should be evaluated by visual inspection of a plot of signals as a function of analyte concentration or content [20]. The linearity of punicalagin standards was studied between 5-50 $\mu \mathrm{M}$ concentration range. The calibration curve was evaluated by its correlation coefficient. The calibration equation and correlation coefficient are $y=8.4354 x-1.0265$ and $(r 2=0.9941)$, respectively, which demonstrated linearity of the method over the concentration range analyzed.

\section{Limit of detection (LOD) and quantification (LOQ):}

The limit of detection (LOD) of an individual analytical procedure is the lowest amount of analyte in the sample which can be detected but not necessarily quantified as an exact value. The limit of quantification (LOQ) is the lowest amount of analyte which can be quantitatively determined with suitable precision. The lowest detection assayed where the signal/noise ratio was at least 3:1, which is regarded as LOD. The LOQ was determined as a signal/noise ratio of 10:1. LOD and LOQ values were found for punicalagin as 0.4 and $1.2 \mu \mathrm{M}$, respectively.

\section{Precision and Accuracy:}

Precision of an analytical method expresses the closeness of agreement between a series of measurements obtained from the same sample under the defined conditions. The precision of the method was determined by repeatability which can be assessed by preparing three samples at three different concentrations in triplicates covering the specified range for the procedure. The precision data is expressed in the form of standard deviation and relative standard deviation (RSD) (Table 1). The accuracy of this analytic method was assessed as the percentage relative error (\% relative error: (foundadded)/added $\times 100$ ).
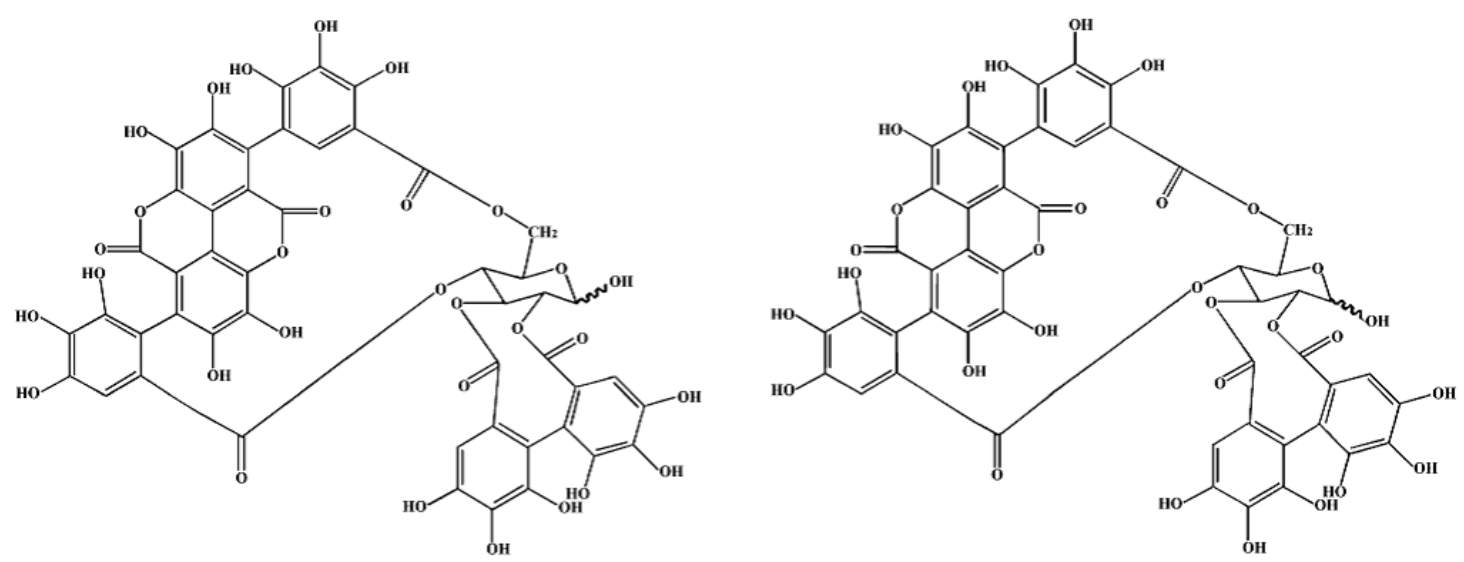

Figure 1. Two isomer structures of punicalagin. $\beta$-punicalagin is on the left and $\alpha$-punicalagin is on the right. 


\section{RESULTS and DISCUSSION}

Punicalagin (2,3-(S)-hexahydroxydiphenoyl-4,6-(S,S)gallagyl-D-glucose) is an ellagitannin, a type of and is phenolic compound found in forms of alpha $(\alpha)$ and beta $(\beta)$ in pomegranates (Punica gratum-L) (Figure 1 ). It is a polyphenol compound which can donate multiple hydrogen atoms to free radicals such as peroxynitrites. As one can assume from its structure, punicalagin is water soluble and therefore the body has no trouble breaking it down. Recent researchers have shown that punicalagin has shown many biological activities related to the prevention and treatment of a wide range of diseases including heart attack and stroke, diabetes and obesity, Alzheimer and brain ischemia due to its anti-oxidant, anti-inflammatory, anti-carcinogenic and an- as a good source of significant biologically active polyphenolic compounds has gained an increased amount of demand which often exceeding supply. Then, adulterating pomegranate juice with other types, usually lower anti-oxidant quality, juices have become a common practice.

In this study, a simple and fast method for the analysis and quantification of punicalagin, the most abundant phenolic compound, from six different brands of pomegranate juices was investigated. Punicalagin identification relied primarily on UPLC/MS method. Efficient chromatographic separation and high performance mass spectrometry are significant to efficiently resolve $(\alpha)$ and $(\beta)$ signals of punicalagin. Replicate injections of the pomegranate sample and punicalagin standards
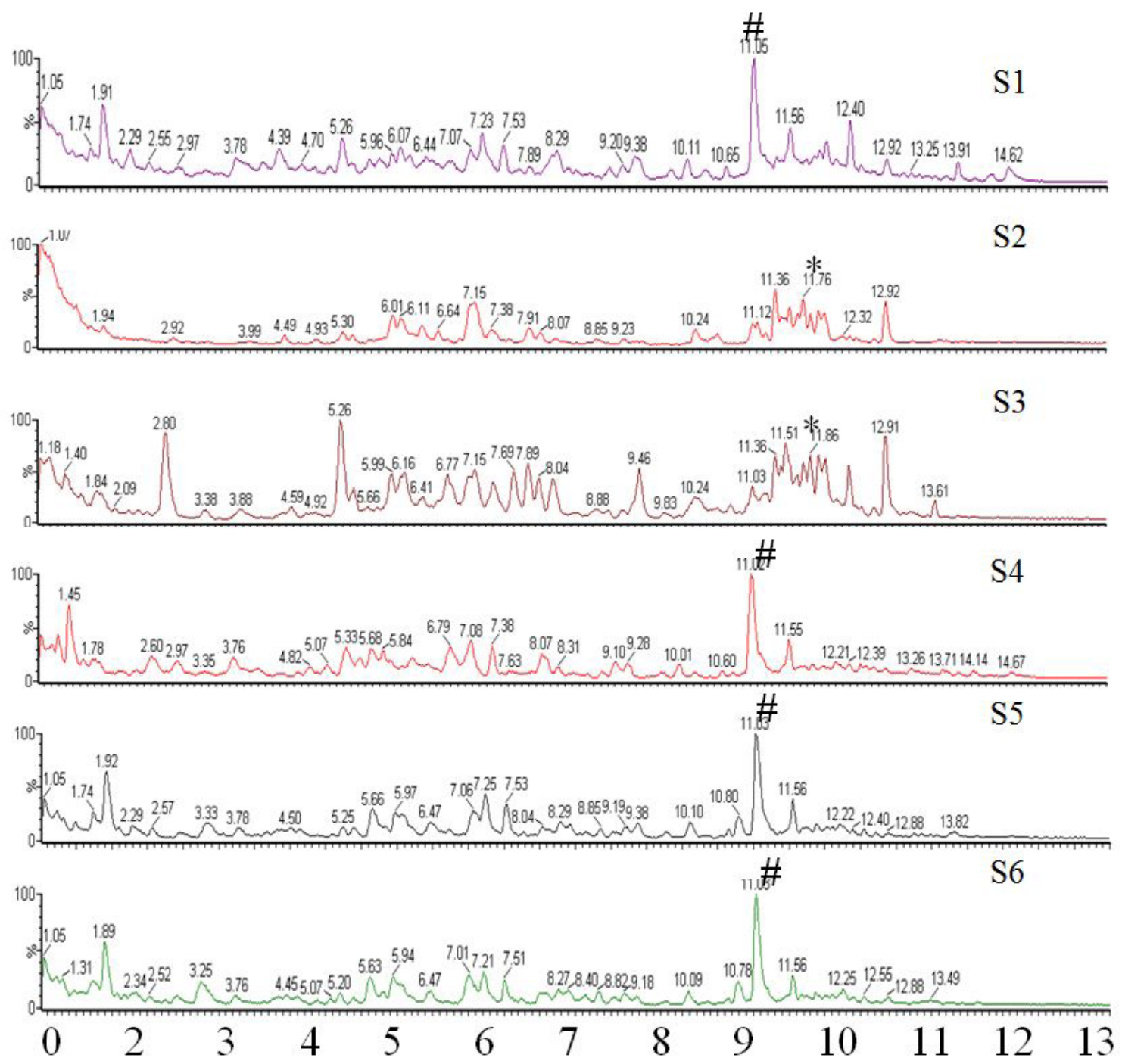

Figure 2. Total ion chromatogram (TIC) of all six pomegranate juice samples (S1-S6) by UPLC-ESI/MS. \# indicates a potential marker for pomegranate juice while * shows a peak pattern that can be used as a potential marker for cranbery juices. 
monitored were directly associated to the samples rather than. Figure 2 shows the total ion chromatogram (TIC) of six different brand of pomegranate juices by UPLC/MS analysis. Two juice samples (S2 and S3) are mixture of pomegranate and cranberry juices. As it can be seen in their TIC chromatogram, the peak at around $11 \mathrm{~min}$. seems to be a potential pomegranate marker. In TIC chromatogram of S2 and S3, there seems to be pattern of peaks around 11-13 min. which can be utilized as a potential marker for cranberry juice. A wide array of different peaks emerged from phenolic acids, anthocyanins, flavonoids, and ellagitannins can be observed in TIC chromatogram, however, this study was aimed to determine and quantify punicalagin content of different brands of pomegranate juices by a simple and fast UPLC/MS method.

First, we have used punicalagin standards to not only optimize separation conditions for $\alpha$ and $\beta$ isomers of punicalagin but also create a calibration curve that would be used for the quantification of punicalagin content from commercial pomegranate juices. Punicalagin stan-
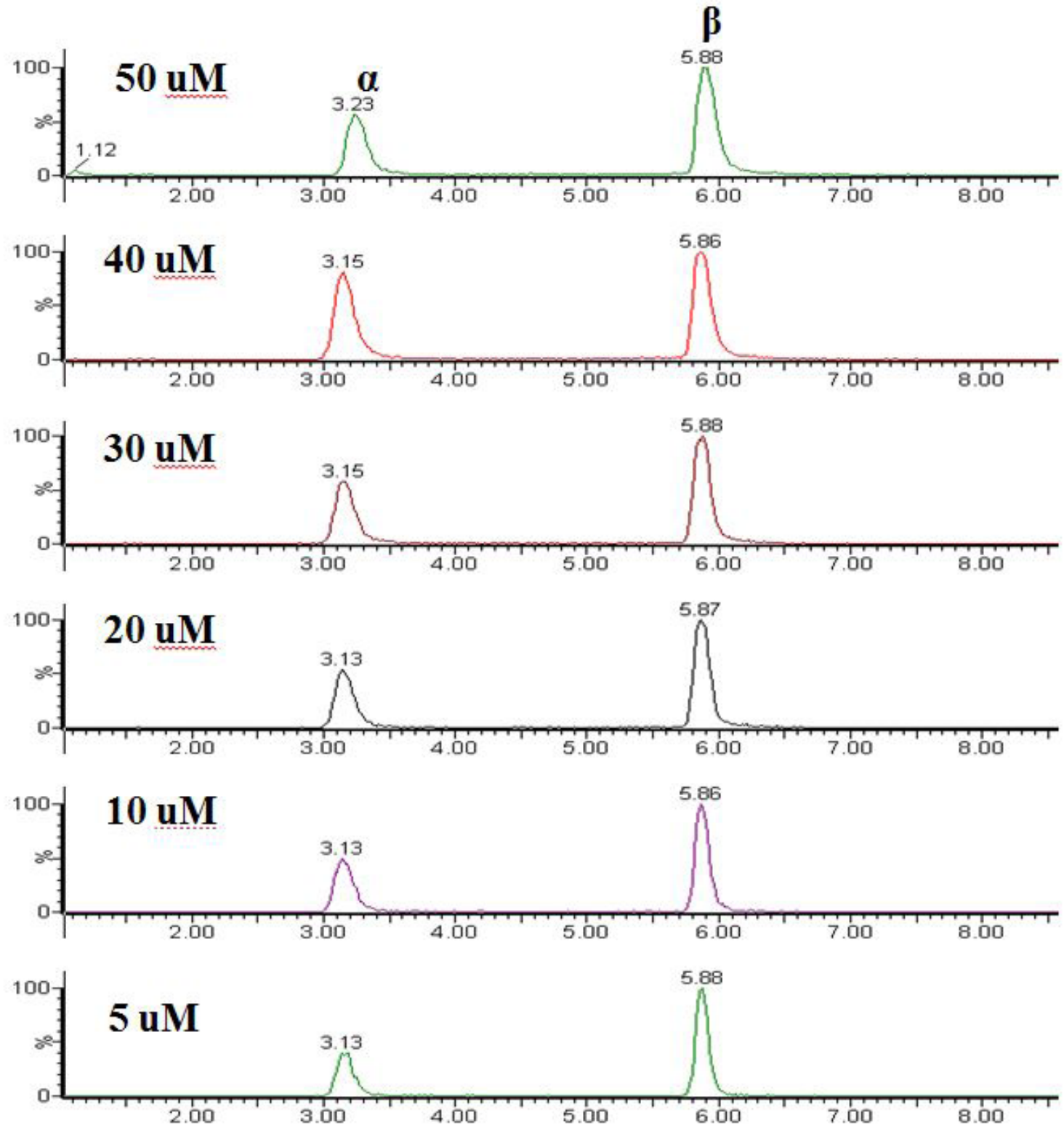

Figure 3. Extracted ion chromatogram (m/z 541) of punicalagin standards. 


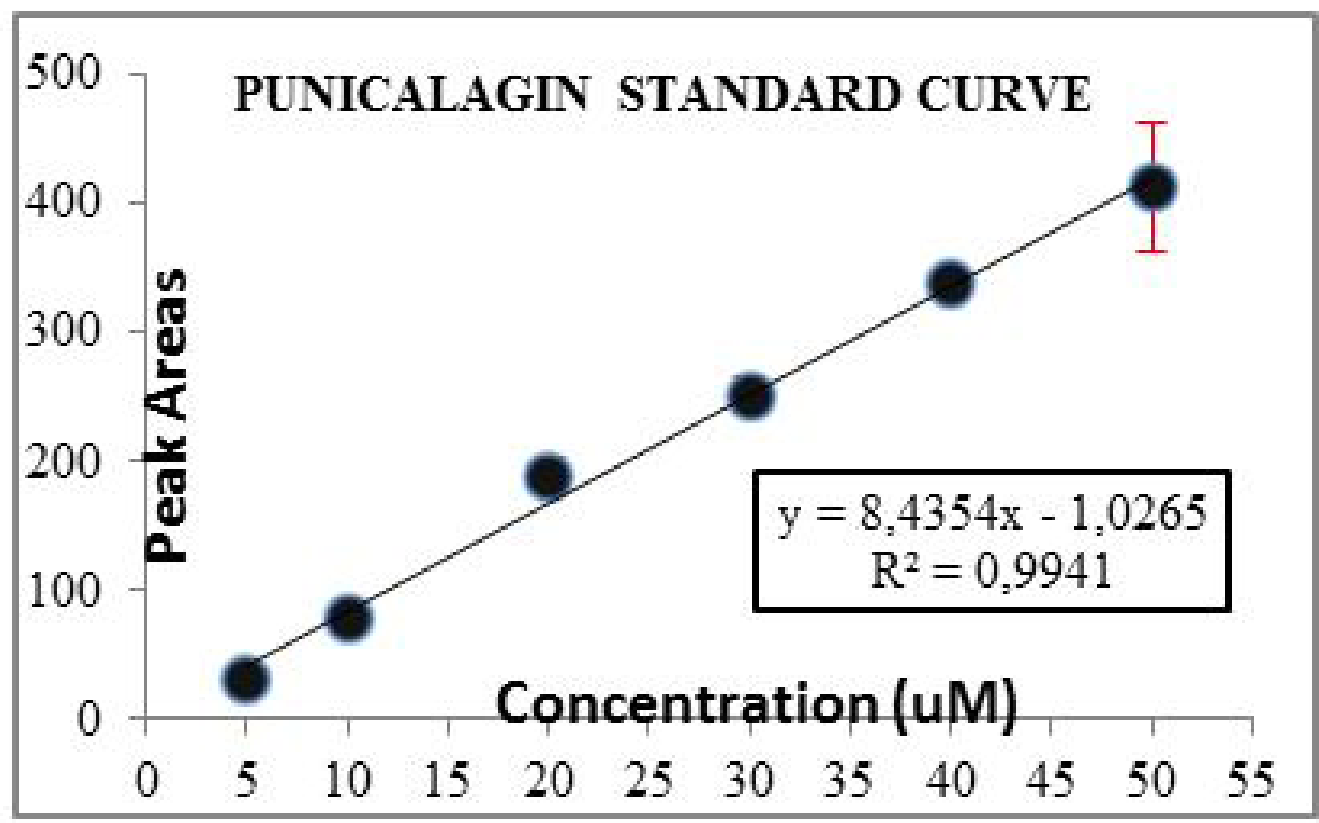

Figure 4. The standard curve of punicalagin standards.

dards were prepared from $50 \mu \mathrm{M}$ to $5 \mu \mathrm{M}$ in buffer $\mathrm{A}$ (0.1\% formic acid in water) were analyzed using Waters BEH C18 column, $1.7 \mu \mathrm{m}$ particle size $(50 \times 2.1 \mathrm{~mm})$. In order to provide the highest ionization efficiency, a punicalagin standard sample was infused directly to mass spectrometry. Mass method conditions were developed by optimizing the MS tune parameters for punicalagin analysis. Initially, standard curve of the punicalagin standards was not ideal with correlation coefficient (R2) value of 0.8736 (data not shown). In particular, when we increased the concentration of punicalagin standards up to $30 \mu \mathrm{M}$, the curve started to diverge from ideal linearity. The unideal standard curve might arise from MS detector saturation, suppression of electropspray ionization and/or possible chemical reactions at higher concentrations. Then we have optimized MS tune parameters by increasing the source ionization voltage from $2.5 \mathrm{kV}$ to $3.0 \mathrm{kV}$, desolvation temperature from $250^{\circ} \mathrm{C}$ to $275^{\circ} \mathrm{C}$ and the source temperature from $100^{\circ} \mathrm{C}$ to $120^{\circ} \mathrm{C}$

After acquiring series of mass spectra under different experimental conditions, the best results were obtained by using following MS tune parameters in negative mode: The source voltage was $3000 \mathrm{~V}$, the desolvation temperature was $275^{\circ} \mathrm{C}$ and source temperature was $120^{\circ} \mathrm{C}$. The mass scan range was $\mathrm{m} / \mathrm{z} 100-1200$. Thus, MS conditions were optimized to obtain best resolution and the highest sensitivity for both $\alpha$ - and $\beta$-punicalagin by using punicalagin standards. Also, Separation of $\alpha$ and $\beta$ isomers of punicalagin was improved by shorter UPLC column (Waters BEH C18 column, $1.7 \mu \mathrm{m}$ particle size, $50 \times 2.1 \mathrm{~mm}$ ). Figure 3 shows extracted ion chromatograms of punicalagin standards ranged from 5 to $50 \mu \mathrm{M}$ (EIC, m/z 541). The punicalagin content was calculated using a standard curve created based on the total peak areas of the $\alpha$ and $\beta$ isomers of punicalagin standards (Figure 4).

Method validation parameters including linearity, precision, accuracy, limit of detection and limit of quantification were investigated according to the $\mathrm{ICH}$ (Guidance for Industry: Bioanalytical Method Validation) [20]. The calibration equation and correlation coefficient are $y=8.4354 x-1.0265$ and $\left(r^{2}=0.9941\right)$, respectively, which demonstrated linearity of the method over the concentration range analyzed. LOD and LOQ values were found for punicalagin as 0.4 and $1.2 \mu \mathrm{M}$, respectively. Table 1 shows the summary of precision and accuracy of the analytic method.

Punicalagin content of six different brands of commercial pomegranate juices was analyzed by UPLC-ESI/MS method described above. Peak assignments of punicalagin from commercial pomegranate juices were made by comparing retention times and $\mathrm{m} / \mathrm{z}$ values with the standards. The predominance of a molecular ion, the 
Table 1. Precision and accuracy of punicalagin.

\begin{tabular}{cccc}
\hline Added $(\mu \mathrm{M})$ & Found \pm SD & \% RSD & \% relative error \\
\hline 10 & $9.8 \pm 0.474$ & 4.84 & 2.00 \\
\hline 30 & $30.5 \pm 1.022$ & 3.35 & 1.66 \\
\hline 40 & $40.3 \pm 0.787$ & 1.95 & 0.75 \\
\hline
\end{tabular}

doubly-charged $\mathrm{m} / \mathrm{z} 541$, in a determined ionization mode is shown in Figure 5. Punicalagin peaks from different brand of pomegranate juices studied by UPLC method seem to show very similar phenolic qualitative profile but their relative abundances were utterly different. EICs of the juice samples used in this study showed it to be observed in all pomegranate samples, however, their concentrations varied (Figure 6). In particular, S2 and S3 juice samples (S2 and S3 samples are cranberry/ pomegranate juice blends) showed the lowest content of punicalagin. For the authentic juices, the levels were much higher, to be more precise 43 -fold, with the highest levels found in the authentic pomegranate juice sample (S1). The punicalagin levels in authentic samples S5 and S6 were very much similar to S1 sample; however, S4 sample indicated very low amount of punicalagin content though it is labeled as an authentic juice sample.

Epidemiological studies recommend that consumption of antioxidant rich fruit or vegetables such as pomeg-
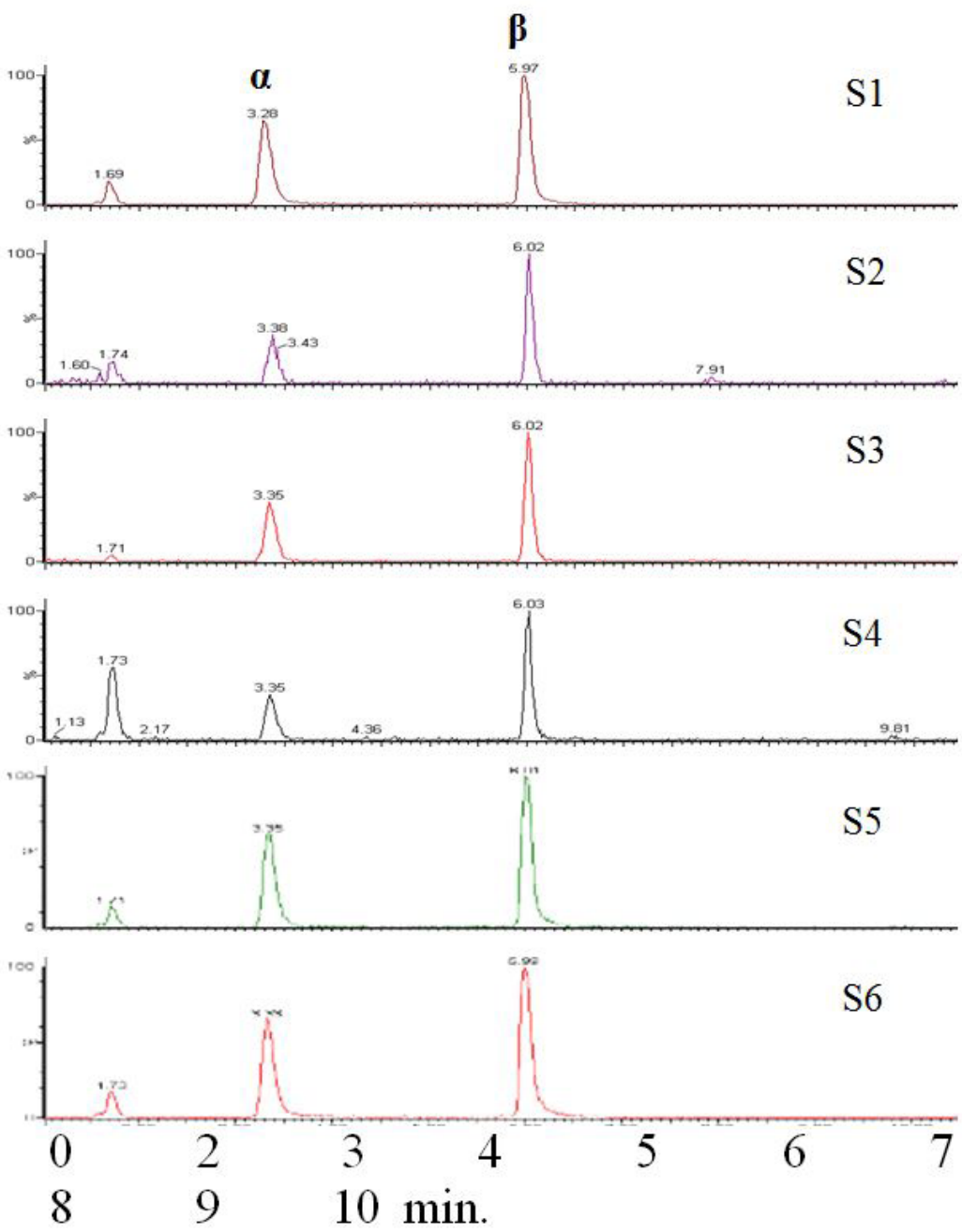

Figure 5. Extracted ion chromatogram (EIC) of punicalagin ( $\mathrm{m} / \mathrm{z} 541)$ from six different commercially available juice samples (S1-S6) by UPLC-ESI/MS. 

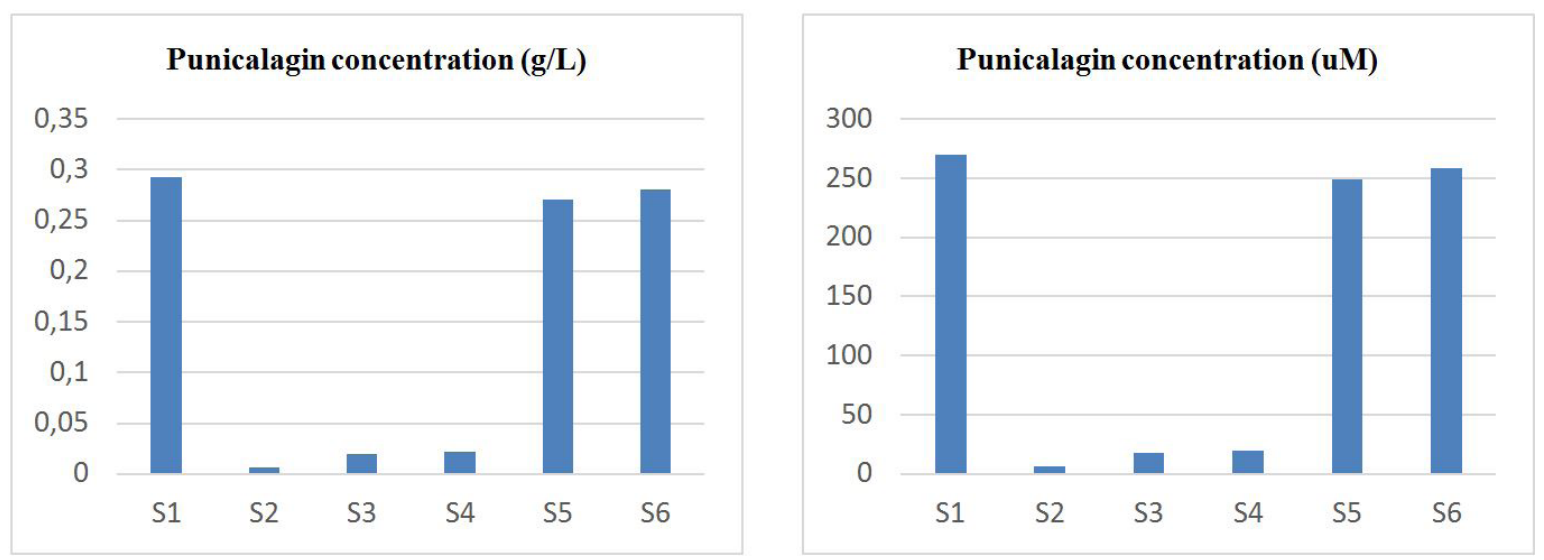

Figure 6. Punicalagin contents of six different brands of pomegranate juices were given by both as $g / L$ and $\mu \mathrm{M}$.

ranate could possibly reduce the risk of cancer. This study represents a contribution to the investigation of punicalagin from commercially available authentic and adulterated juice samples by a fast and repeatable UPLC method. The separation and accurate quantification of the $\alpha$ and $\beta$ isomers of punicalagin was improved utilizing a shorter column. Three mass tune parameters including ionization voltage, desolvation temperature and source temperature of ESI source were optimized to obtain better peak shapes and correct quantification of the $\alpha$ - and $\beta$-isomer peaks of punicalagin. The punicalagin content from six different juice samples was analyzed and it was shown that punicalagin levels from six different brand of pomegranate juices varied from 0.007 to $0.3 \mathrm{~g} / \mathrm{L}$ which seems to be lower than what it was reported previously $(0.017$ to $2 \mathrm{~g} / \mathrm{L})$. These results might indicate that some newer juices that are now available in stores might require easy but accurate testing methods. The proposed study may be useful to determine this anti-oxidant compound during shelf life of juices with fast and effective manner. Besides, some peaks could be valuable marker for the quality of pomegranate juice authenticity; however, additional experiments are required to identify these compounds.

\section{References}

1. J.S. Jurenka, Therapeutic applications of pomegranate (Punica granatum L.), Altern. Med. Rev., 13 (2008) 128-144.

2. S. Medjakovic, A. Jungbauer, Pomegranate: a fruit that ameliorates metabolic syndrome, Food Funct., 4 (2013) 19 39.

3. E. Turrini, L. Ferruzzi, C. Fimognari, Potential effects of pomegranate polyphenols in cancer prevention and therapy, Oxid. Med. Cell Longevity, (2014) 1-20.
4. G. Ma, C. Wang, L. Li, N. Ding, X. Gao, Effect of pomegranate peel polyphenols on human prostate cance PC-3 cells in vivo, Food Sci. Biotechnol., 24 (2015) 1887-1892.

5. S. Banihani, S. Swedan, Z. Alguraan, Pomegranate and type 2 diabetes. Nutr. Res. 33 (2013) 341-348

6. S.R. Katz, R.A. Newman, E.P. Lansky, Punica granatum: heuristic treatment for diabetes mellitus, J. Med. Food., 10 (2007) 213-217.

7. M.I. Gil, F.A. Tomas-Barberan, B. Hess-Pierce, D.M. Holcroft, A.A. Kader, Antioxidant activity of pomegranate juice and its relationship with phenolic composition and processing, J. Agric. Food Chem., 48 (2000) 4581

8. S.T. Lee, Y.L. Wu, L.H. Chien, S.T. Chen, Y.K. Tzeng, T.F. Wu, Proteomic exploration of the impacts of pomegranate fruit juice on the global gene expression of prostate cancer cell, Proteomics, 12 (2012) 3251-3262.

9. V. Di Stefano, R. Pitonzo, M.E. Novara, D. Bongiorno, S. Indelicato, C. Gentile, G. Avellone, R. Bognanni, S. Scandurrac, M.G. Melillic, Antioxidant activity and phenolic composition in pomegranate (Punica granatum L.) genotypes from south Italy by UHPLC-Orbitrap-MS approach, 99 (2019) 10381045.

10. J. Lu, K. Ding, Q. Yuan, One-step purification of punicalagin by preparative hplc and stability study on punicalagin, Sep. Sci. Technol., 46 (2011) 147-154.

11. M. Rosenblat, M. Aviram, N.P. Seeram, D. Heber, In vitro studies in pomegranates: ancient roots to modern medicine,Taylor and Francis Group, New York, 2006, 31-43.

12. M. Aviram, L. Dornfeld, M. Rosenblat, N. Volkova, M. Kaplan, R. Coleman, T. Hayek, D. Presser, B. Fuhrman, Pomegranate Juice consumption reduces oxidative stress, atherogenic modification to Idl and platelet aggregation: studies in human and in atherosclerotic apolipoprotein deficient mice, Am. J. Clin.Nutr., 71 (2000) 1062-1076.

13. E. Poyrazoglu, V. Gokmen, N. Artuk, Organic acids and phenolic compounds in pomegranates (Punica granatum) grown in Turkey, J. Food. Comp. Anal., 15 (2002) 567-575.

14. S. Madrigal-Carballo, G. Rodriguez, C.G. Krueger, M. Dreher, J.D. Reed, Pomegranate (Punica granatum) supplements: Authenticity, antioxidant and polyphenol composition, J. Funct. Foods, 1 (2009) 324-329. 
15. P. Mena, L. Calani, C. Dall'Asta, G. Galaverna, C. GarcíaViguera, R. Bruni, A. Crozier, D. Del Rio, Rapid and comprehensive evaluation of (Poly) phenolic compounds in pomegranate (Punica granatum L.) juice by UHPLC-MS, Molecules, 17 (2012) 14821-14840.

16. U.A. Fischer, R. Carle, D.R. Kammerer, Identification and quantification of phenolic compounds from pomegranate (Punica granatum L.) peel, mesocarp, aril and differently produced juices by HPLC-DAD-ESI/MSn, Food Chem., 127 (2011) 807-821.
17. M. Wohig, A. Gledhill, J. Burgess, The determination of fruit juice authenticity using high resolution chromatography, uv, time-of-flight ms, and multivariate analysis [Online] Waters Corporation 2011.

18. J. Lu, Y. Wei, Q. Yuan, Preparative separation of punicalagin from pomegranate husk by high-speed countercurrent chromatography, J. Chrom. B, 857 (2007) 175-179.

19. J. Lu, K. Ding, Q. Yuan, Determination of punicalagin isomers in pomegranate husk, Chromatographia, 68 (2008) 303-306.

20. H.V. Paithankar, HPLC method validations for pharmaceuticals: A review. IJUPBS. 2013 229-240. 